\title{
SAÚDE E QUALIDADE DE VIDA: DISCURSOS DE DOCENTES NO COTIDIANO DE UMA ESCOLA PÚBLICA DE SANTA CATARINA
}

\author{
HEALTH AND QUALITY OF LIFE:TEACHERS' SPEECHES IN DAILY LIFE OF A PUBLIC SCHOOL IN \\ SANTA CATARINA
}

\section{SALUD Y CALIDAD DE VIDA: DISCURSOS DE DOCENTES EN EL COTIDIANO DE UNA ESCUELA PÚBLICA DE SANTA CATARINA}

\author{
Ioná Outo de Souza Wilberstaedt ${ }^{1}$ \\ Marcia Gilmara Marian Vieira ${ }^{2}$ \\ Yolanda Flores e Silva ${ }^{3}$
}

Resumo A pesquisa teve por objetivo conhecer as concepções sobre saúde, doença, qualidade de vida e temas afins de docentes de uma escola pública de Florianópolis, Santa Catarina, Brasil, 2013. Estudo qualitativo, descritivo, com dados coletados por meio de grupo focal e entrevistas semiestruturadas. A estratégia de grupo focal adotada foi orientada segundo a abordagem do 'círculo de cultura', no qual os participantes expressaram suas concepções sobre os temas estudados e refletiram sobre como contribuir com estratégias de promoção da saúde no contexto escolar por meio da educação em saúde. O universo da pesquisa foi formado por 16 docentes da rede estadual de ensino; oito docentes confirmaram a participação no grupo focal e, desses, apenas seis compareceram do primeiro ao último encontro. Ao final os dados revelaram que os docentes percebem uma estreita relação entre saúde e qualidade de vida e que uma vida saudável é possível na presença de enfermidade. Enfatizaram a necessidade de maior participação dos pais e profissionais da saúde no processo de educação em saúde e, também, de um preparo sistemático e permanente sobre as questões que envolvam saúde no contexto escolar. As concepções dos docentes reafirmam que a dimensão social sobressai à biológica e que o conhecimento e a valorização desses aspectos, na prática docente, podem ampliar as ações em saúde.

Palavras-chave saúde; qualidade de vida; docentes.
Abstract The research aimed to know the conceptions of health, disease, quality of life and other topics in teachers of a public school in Florianópolis, Santa Catarina, Brazil, 2013. A qualitative and descriptive study was carried out with data collected in focus group and semi-structured interviews. The focal group strategy was oriented on the approach of the 'circle of culture', in which the participants expressed their concepts on the studied themes and reflected on how to contribute to health promotion strategies in the school context through education on health. The research universe included 16 teachers from state schools; eight teachers confirmed their participation in the focus group and, of these, only six attended the first to the last meeting. At the end, the data revealed that teachers perceive a close relationship between health and quality of life and that a healthy life is possible in the presence of disease. They emphasized the need for greater participation of parents and health professionals in the health education process and also a systematic and continuing preparation on issues involving health in the school context. Conceptions of teachers reaffirm that the social dimension exceeds the biological one and that knowledge and appreciation of these aspects, in teaching practice, can broaden health actions. Keywords health; quality of life; teachers. 


\section{Introdução}

Semelhante ao que ocorre no mundo, o debate sobre saúde, qualidade de vida, bem-estar e doença não é recente no Brasil. As conferências nacionais de saúde, os debates políticos, a própria criação do Sistema Único de Saúde (SUS) e a Constituição de 1988 fortaleceram a Reforma Sanitária. Porém, ainda há uma instabilidade conceitual a respeito do processo saúde-doença, dificultando as ações em saúde.

Segundo Canguilhem (2009), existe uma noção do que é ser saudável relacionada com o que se considera como 'normal' sempre em oposição ao que se afirma como 'não saudável'. Por sua vez, o que se afirma como 'doença' ou 'patológico' é sempre anormal. Tanto nas práticas de saúde quanto nos conceitos, existe uma resistência em conceituar saúde como ausência de doença até mesmo em nossos dias. Inclusive, os argumentos corporativos sobre saúde privilegiaram a classe médica no século XVIII. De acordo com Foucault (2008), na Europa Ocidental, faziam intervenções julgando saberem o que seria saudável ou não para as pessoas.

O próprio SUS se apropria do modelo biomédico, implantando práticas assistencialistas, biologistas e deterministas, o que não favorece as ações integradas e integrativas voltadas para a promoção e a educação da saúde. Nessa perspectiva, discute-se a necessidade de ampliar o conceito de saúde por meio da valorização do ser humano como um 'ser uno' e multidimensional, capaz de se manter saudável ou viver com saúde mesmo estando numa condição de doença (Dalmolin et al., 2011).

O campo da educação é bastante vasto e propício para o desenvolvimento de ações de promoção e educação em saúde. As escolas são espaços socialmente reconhecidos para o desenvolvimento de atos pedagógicos, podendo contribuir na construção de valores pessoais e nos significados atribuídos a objetos e situações, dentre eles a saúde. A escola saudável pode tornar-se um ambiente solidário e propício ao aprendizado, engajando-se no desenvolvimento de políticas públicas saudáveis e na inclusão da população em projetos de promoção da saúde (Aerts et al., 2004).

A escola pode ser, portanto, um ambiente para o desenvolvimento de projetos que visem à qualidade de vida das pessoas nos espaços em que elas convivem, trabalhando num esforço contínuo de corresponsabilidade (o sistema de saúde, o governo, a escola, os docentes, as famílias e os alunos) para a promoção e a educação em saúde. Essa corresponsabilidade contrapõe-se à ideia de responsabilidade pessoal e individual como sugerida, por exemplo, por Gomes (2009). Esse autor sugere que as ameaças à saúde de jovens nos anos de 1991 a 2000 são oriundas, principalmente, de condutas e de comportamentos prejudiciais à sua saúde, com comportamentos de risco mais precoces que em outras gerações, e que a maioria dessas condutas pode ser 
evitada. A grande questão sobre o conceito ampliado de saúde é a de se as questões inerentes ao processo de saúde envolvem apenas atitudes pessoais.

Quando partimos do pressuposto de que o estado de saúde está relacionado com o comportamento das pessoas, a dinâmica na promoção da saúde deve ser direcionada a evitar condutas e comportamentos que levem ao risco. Porém, se o estado de saúde está relacionado com outras dimensões além das comportamentais, como a determinação social, faz-se necessário repensar as práticas e refletir sobre os processos do viver humano. Para Campos e Rodrigues Neto (2008), os comportamentos humanos que determinam nossas concepções acerca da saúde, doença ou qualidade de vida podem ser influenciados por dimensões mais genéricas ou mais específicas. O importante, ao fazermos uma análise sobre essas concepções, é que vejamos como as mesmas são interligadas e interdependentes.

Na pesquisa realizada, da coleta à análise dos dados, o objetivo geral que norteou a investigação foi o de conhecer as concepções sobre saúde, doença, qualidade de vida e temas afins de docentes de uma escola pública de Santa Catarina, tendo como meta final o desenvolvimento de atividades de educação em saúde. A intenção também foi de levar esses docentes a refletirem sobre suas concepções pessoais e implicações na prática profissional. Queríamos que questionassem não só o processo saúde e doença que vivenciam em seus cotidianos de vida, mas também, ao mesmo tempo, a saúde de alunos, familiares e comunidade - e o papel da escola nesse processo.

\section{Metodologia}

O percurso metodológico adotado foi o qualitativo de cunho exploratório-descritivo. Segundo Minayo e Sanches (1993), as tarefas e os desafios dos cientistas sociais que utilizam a abordagem qualitativa têm sido definir o nível simbólico dos significados e da intencionalidade, constituindo-o como um campo de investigação que auxilia no desenvolvimento de métodos e técnicas que sistematizam o processo de pesquisa da coleta à análise. Minayo (2007) afirma que as metodologias qualitativas são capazes de incorporar os significados e intencionalidades aos atos, relações e estruturas sociais, traduzidas como construções sociais humanas significativas. Quando a metodologia qualitativa é aplicada na saúde, ela busca entender os significados dos fenômenos em seu âmbito individual ou coletivo, e não os fenômenos em si, pois a compreensão dos significados tem uma função estruturante para as pessoas, sabendo-se que elas organizam suas vidas com base nesses significados (Turato, 2005).

A coleta de dados compreendeu a realização de grupos focais e entrevistas semiestruturadas no ano 2013. Iniciamos com a formação do grupo 
focal, entendendo-o como uma forma de coleta de falas de um grupo que relata suas experiências e percepções em torno de um tema em questão (Perosa e Pedro, 2009).

A dinâmica do grupo focal consiste na interação entre pesquisador e participantes, com a realização de uma discussão focada em objetivos específicos e diretivos (Aschidamini e Saupe, 2004). A estratégia de grupo focal adotada foi orientada segundo a abordagem do 'círculo de cultura' de Paulo Freire (1983), com os participantes sendo incentivados a expressar suas concepções acerca da saúde, bem-estar, qualidade de vida e doença, além de refletirem sobre como poderiam contribuir para estratégias de promoção à saúde dentro do contexto escolar por meio da educação em saúde.

O grupo partiu de uma reflexão sobre as pessoas e o seu meio de vida, avaliando a situação das mesmas no seu ambiente concreto (a escola, a comunidade), de modo que pudessem perceber conscientemente a sua realidade e assim, como sugere Freire (2008), emergir de forma consciente e comprometida, prontos para pensarem como intervir e mudar a realidade do cotidiano em que vivem. O roteiro de entrevista utilizado para a coleta de dados individual foi semiestruturado com questões abertas, nas quais os docentes puderam respondê-las de acordo com o que pensavam e da maneira como gostariam de se expressar.

Todas as atividades em grupo ou entrevistas individuais foram realizadas no ambiente escolar, por conta da dificuldade de deslocamento dos participantes em razão da carga de trabalho. As entrevistas foram realizadas seguindo o pressuposto de Minayo (2009) de que a entrevista é uma conversa a dois ou entre vários interlocutores, inicialmente direcionada pelo entrevistador, com a intenção de construir informações pertinentes para o objeto e com a possibilidade de discorrer sobre o tema no tempo que se considerar necessário.

Segundo os critérios definidos na proposta, o universo da pesquisa foi formado por 16 docentes de uma escola estadual da capital catarinense de ensino fundamental, com tempo superior a cinco anos de magistério (em serviço público ou privado), que possuíam maior vínculo com o estado e que já haviam trabalhado com educação em saúde. A princípio, oito docentes confirmaram a participação no grupo focal e, deles, apenas seis compareceram do primeiro ao último encontro. Iniciamos a pesquisa partindo do pressuposto de Nogueira-Martins e Bogus (2004) de que o grupo focal é operacional quando composto por no mínimo seis e no máximo 15 pessoas, com duração média de 90 minutos, não ultrapassando três horas para que seja funcional e mantenha o foco no problema/objeto de reflexão.

Em virtude de outros vínculos empregatícios e da dificuldade de acesso ao local planejado, os docentes não concordaram com a proposta inicial de realizar o grupo em um lugar distante do ambiente da escola. A proposta feita por eles de realizar os encontros nas dependências da escola em uma sala 
destinada a atividades pedagógicas foi aceita. Foram realizados quatro encontros com duração de três horas cada: os dois primeiros em dias consecutivos e os dois encontros posteriores em dias intercalados, totalizando 12 horas de formação de grupo focal. Cada sessão iniciava com dinâmica de grupo precedida de conversas, momento de confraternização, momento de construção coletiva, ginástica laboral ou técnica de relaxamento.

Durante as atividades do grupo focal, os docentes foram convidados a participar da pesquisa individual com o mesmo tema. Todos os componentes do grupo prontificaram-se a participar, porém, a critério da pesquisa, somente quatro foram abordados individualmente. A proposta de entrevista individual foi realizada para que pudéssemos confrontar os resultados a fim de confirmar a consistência dos dados coletados no coletivo.

As entrevistas foram realizadas a pedido dos participantes quando disponibilizavam de tempo para uma conversa aberta, em uma sala de recepção da escola de maneira descontraída e informal. Cada entrevista durou cerca de trinta minutos e foi realizada em dias diferentes, conforme cronograma do docente. Todas as entrevistas e conversas do grupo focal foram gravadas e posteriormente transcritas.

A análise das respostas fornecidas no grupo focal e individualmente foi realizada segundo o método interpretativo de Geertz (1997). Para o autor, a análise inicia-se na coleta de dados propriamente dita, quando o pesquisador já vai organizando as falas de modo a obter as respostas para os seus objetivos. Cabe ao pesquisador criar as tramas entre as falas e descrever o que faz sentido, sabendo que existem estruturas significantes nos gestos, olhares, tom de voz e comportamentos que vão além das falas. A forma de organizar os resultados, de apresentá-los e refletir sobre eles pôde ser realizada como considerada mais didática ao leitor modelo ou às pessoas a quem se dirige a pesquisa.

A fim de preservar a identidade dos participantes, a descrição das falas apresentadas nos resultados e na discussão foi identificada como do Professor Participante (PP1, PP2, PP3, PP4, PP5 e PP6) seguida da identificação 'GF', quando coletada no grupo focal, e 'EI' quando coletada na entrevista individual.

A pesquisa4 foi registrada na Plataforma Brasil e submetida e aprovada pelo Comitê de Ética da Universidade do Vale do Itajaí segundo o parecer n. 446.060 em 25/10/2013.

\section{Resultados e discussão}

A realização de um trabalho coletivo interdisciplinar requer a interação das pessoas que constituem o corpo de profissionais que reflete a sua prática e, mais, que se tenha uma lógica de trabalho equânime e uma discussão coletiva 
sobre o que se pretende trabalhar. No caso da escola em que se realizou a investigação aqui descrita, pensar a educação em saúde numa perspectiva de promoção da saúde e prevenção da doença requer que o corpo docente não apenas reflita sobre como elaborar uma proposta de trabalho na escola em que atua, mas também sobre a sua vida nesse processo que denominamos de saúde e doença. Ao mesmo tempo, ainda é preciso trabalhar as suas concepções acerca das temáticas que fazem parte de toda a discussão sobre o que seja saúde, doença, qualidade de vida, entre outros elementos importantes.

A discussão e a reflexão sobre saúde e qualidade de vida entre docentes de uma escola pública representa um avanço nas escolas principalmente quando esta discussão ocorre com os profissionais da saúde pública (Rocha e Fernandes, 2008). É importante ressaltar que a educação em saúde não deve ficar restrita às esferas das instituições públicas de saúde, tais como as unidades básicas representadas pelos postos e centros de saúde ou os ambulatórios de hospitais públicos. Todos os setores deveriam ter pessoas e espaços para discutir o processo saúde e doença nas suas várias interfaces e convergir os interesses para essa área, visto que trabalhar nessa perspectiva, principalmente em uma escola, pode fortalecer e ampliar as ações em saúde, tanto coletivas quanto individuais, seja com os docentes, alunos e servidores, seja com a comunidade localizada no entorno da escola.

A pesquisa ocorreu com esse olhar e antes de mostrarmos os resultados e a reflexão concomitante, apresentamos o perfil da escola e dos docentes que participaram da pesquisa.

\section{A escola: perfil socioespacial e apresentação dos docentes}

A escola está inserida há cinquenta anos no bairro Capoeiras em Florianópolis. Está bem localizada e, para se chegar a ela, é possível contar com uma oferta grande de transportes coletivos nas proximidades, com fácil acesso pela Via Expressa (BR-282) e demais avenidas quando utilizado transporte próprio. Além disso, há opções de restaurantes e outros serviços bem próximos, tais como farmácias, bancos, lanchonetes, supermercados, lojas de artigos domésticos, clínicas, salão de beleza, entre outras pequenas empresas e comércios. Sua infraestrutura é considerada satisfatória pelos docentes e demais funcionários, contendo dez salas de aula, uma sala de computação e vídeo, uma sala de multimídia, depósito, uma quadra descoberta e cozinha.

O quadro de funcionários é composto basicamente por docentes, área administrativa (direção, assessoria de direção, secretárias) e serviço terceirizado de segurança, higiene e alimentação. No Quadro 1, traça-se um perfil resumido dos participantes da pesquisa. A carga horária apresentada mostra o total de horas aulas trabalhado semanalmente e dedicado à escola, 
com exceção do caso de dois professores efetivos, cuja carga horária total contempla também atividades em outras escolas privadas. Os participantes têm idade entre 30 e 50 anos, dois não têm filhos e dois são solteiros. Desses, quatro dependem exclusivamente do transporte público para irem de casa para o trabalho e vice-versa.

Quadro 1

\begin{tabular}{|l|c|c|c|c|c|}
\hline \multicolumn{2}{|l}{ Perfil dos docentes participantes da pesquisa, Florianópolis, 2013} \\
$\begin{array}{c}\text { Formação } \\
\text { profissional }\end{array}$ & Atuação & Pós-graduação/Outra graduação & $\begin{array}{c}\text { Tempo de } \\
\text { magistério }\end{array}$ & $\begin{array}{c}\text { Carga } \\
\text { horária }\end{array}$ & Vínculo empregatício \\
\hline Letras-Inglês & Língua Inglesa & Especialização Interdisciplinaridade na Sala de Aula (Não concluída) & 18 anos & $59 \mathrm{~h}$ & Efetivo \\
Pedagogia & Artes & Artes (em andamento) & 5 anos & $40 \mathrm{~h}$ & Admitido em caráter temporário \\
Pedagogia & Professor regente & Não possui & 25 anos & $20 \mathrm{~h}$ & Admitido em caráter temporário \\
Pedagogia & Professor regente & Especialização: Mídias na Educação (em andamento) & 8 anos & $40 \mathrm{~h}$ & Admitido em caráter temporário \\
Pedagogia & Professor regente & Não possui & 23 anos & $40 \mathrm{~h}$ & Admitido em caráter temporário \\
Geografia & Geografia & Especialização em Psicopedagogia & 9 anos & $40 \mathrm{~h}$ & Efetivo
\end{tabular}

Fonte: Os autores.

\section{Concepções de saúde e doença}

Para obtermos as respostas desejadas quanto às concepções segundo nossos objetivos, realizamos encontros coletivos em formato de grupo focal e entrevistas individuais. Nesses encontros, posicionamo-nos apenas como agentes mediadores da discussão e entrevista, sem interferir no pensamento das pessoas e facilitando uma discussão centrada nos objetivos propostos.

Como questão inicial, indagou-se aos docentes acerca de suas concepções sobre os quatro fenômenos do viver humano - saúde, doença, bem-estar e qualidade de vida -, e como essas concepções poderiam contribuir para as práticas de educação em saúde na escola. Importante esclarecer que pensamos na educação em saúde como um elemento importante da promoção da saúde, que tem como objetivo norteador capacitar a comunidade para o cuidado da sua qualidade de vida em todas as instâncias da sociedade. Significa dizer que Estado, comunidade, famílias e pessoas devem ser parceiros e, juntos, articular-se de modo a lutar por políticas públicas que levem as pessoas a terem melhor qualidade de vida (Machado et al., 2007; Buss, 2000).

Ao se analisarem as falas, percebeu-se que os professores se sentem fortalecidos quando tratam dos assuntos de sua experiência pessoal e profissional na coletividade, ao mesmo tempo em que demonstram fragilidade, 
insegurança e aborrecimento nas falas individuais. Essa atitude se explica, segundo Araújo e Rocha (2007), porque há um mecanismo de construção no trabalho em equipe pelo qual um profissional transforma sua prática reconstruindo-se na prática do outro até serem ambos transformados para a atuação no contexto onde estão inseridos. As falas, que se tornam coletivas ou em grupo, são dirigidas de forma a estimular o pensamento do outro com argumentos complementares para a solução de problemas comuns a todos e todas. Quando esse tipo de fala ocorre, há uma maior disposição para ouvir e sustentar a opinião do grupo - esse é um dos momentos em que todos se mostravam dispostos à colaboração e encorajados ao exercício da profissão.

Dos seis integrantes do grupo, cinco concordam que saúde não é ausência de doença, e todos os docentes afirmam que qualidade de vida está associada ao bem-estar físico, mental, social e espiritual. Nos depoimentos, percebe-se claramente que a categoria saúde está em oposição à de doença, ao mesmo tempo em que neles se entrelaçam as concepções sobre esses dois elementos, associando-se, em alguns momentos, às categorias bem-estar e qualidade de vida como parte de um discurso de gostar do trabalho, do que se faz etc. (Figura 1).

Figura 1

Categorias relacionadas à saúde

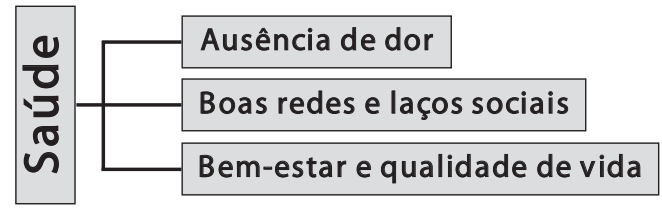

Fonte: Os autores.

Sobre como a categoria saúde é concebida pelos docentes, percebemos que falar de saúde não equivale a falar de não doença. Na verdade, o falar de saúde até implica afirmar ter uma doença (a hepatite, por exemplo), mas, ao mesmo tempo, foge-se da conceituação biomédica da doença, dizendo-se que se uma pessoa não se 'abate' e tem 'amigos, família, metas e objetivos', ela não se sente doente. Ou seja, essa pessoa se vê como alguém que supera o diagnóstico por meio, principalmente, da sua rede de relações sociais. Para Ayres (2007), essa é uma forma de a pessoa se perceber além da racionalidade 
biomédica, colocando sua subjetividade como parte do processo de viver com bem-estar e qualidade de vida mesmo tendo um diagnóstico de doença.

Ao mesmo tempo, mediante expressões-chave, os docentes demonstram ainda que a saúde tem a ver com uma negação da doença à qual Lefévre e Lefévre (2004) denominam de negação da negação. Ou seja, eu nego a doença porque não tenho como cuidar melhor do problema além daquilo que vivo neste meu momento da vida; portanto, tento obter compensações tendo um olhar positivo que nega de certa forma a 'racionalidade' médica dos problemas de saúde que o diagnóstico oferece como resposta aos sintomas que carrego em meu cotidiano. Sobre a categoria 'doença', percebem-se os elementos elencados na Figura 2.

Figura 2

Categorias relacionadas à doença

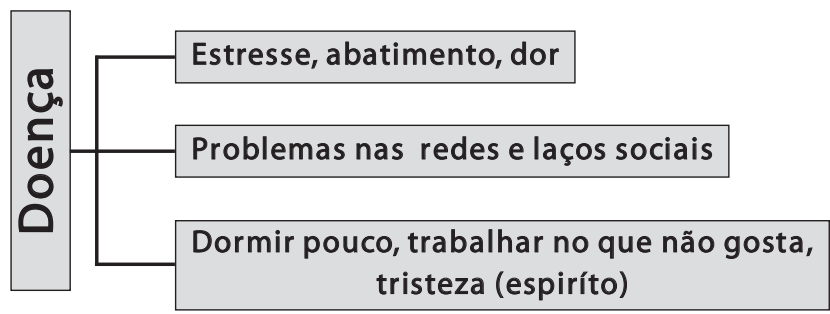

Fonte: Os autores.

Da mesma forma que a categoria saúde, doença não significa exatamente falar de um diagnóstico. Os fenômenos percebidos como doenças estão relacionados a alguns símbolos e significados da experiência cotidiana dos docentes. A dor representa a experiência corporal da doença e o excesso de trabalho o 'dormir pouco'. A tristeza de ter que trabalhar mesmo sem gostar do trabalho que desempenha representa a experiência emocional e espiritual da doença. Essas concepções de saúde e doença estão associadas a um modelo cultural de perceber o processo saúde e doença com símbolos que refletem o arcabouço cultural das pessoas. Sabemos que as preocupações com a saúde e a doença são universais, contudo, cada grupo cria elementos para entender e explicar seus problemas e inclusive os caminhos a seguir para chegar a uma solução (Helman, 2014). A grande pergunta a fazer então é se os docentes pensam dessa forma porque sua cultura lhes ensinou essa 'linguagem' de doença. É óbvio que não responderemos agora essa questão, 
porque outras falas e discursos ainda serão refletidos neste tópico e, com eles, vamos tentar ver os muitos caminhos que existem para se pensar a saúde e a doença (Langdon e Wiik, 2010).

Fazendo um paralelo com o conceito da Organização Mundial da Saúde (OMS) de que "saúde é um estado de completo bem-estar físico, mental e social, e não consiste apenas na ausência de doença ou de enfermidade" (Organização Mundial da Saúde, 1946), percebemos, com a pesquisa, que a pessoa não necessita ter um 'estado completo' das características mencionadas pela OMS para ter saúde, surgindo outro componente de muita importância para os pesquisados: o espiritual. Isso reforça ainda mais a característica dinâmica e complexa que envolve os fenômenos do viver.

Quando interrogados sobre o adoecer e a doença, os docentes não demonstraram nenhuma resistência ao argumentar sobre o assunto, relatando fatos de sua vida cotidiana sem nenhum pudor, fazendo desse momento uma forma de desabafo e testemunho pessoal. Apenas uma pessoa do grupo relatou doença como uma experiência que compromete o físico unicamente. O estigma da doença é superado pelas condições da vida pessoal e coletiva, e todos manifestam que, ainda que sua condição física esteja debilitada ou limitante, os seus ideais precisam ser alcançados até mesmo como forma de superação da própria doença.

Para Nahas, Barros e Francalacci (2000), reagimos positivamente ao estresse quando nossos valores, propósitos de vida e relacionamentos estão equilibrados e nos fazem sentir bem-estar. Para os autores é preciso um ponto de equilíbrio para reagir com segurança e tranquilidade ao estresse. O que afeta a nossa vida é a maneira como reagimos aos agentes estressantes e não o estresse propriamente dito.

Os mecanismos estressores advindos da experiência profissional recebem respostas diferenciadas dos docentes. Isso porque, segundo Margis et al. (2003), as respostas cognitivas dos indivíduos a esses eventos são pessoais e partem da simbolização feita sobre o evento. Essa compreensão reforça ainda mais a necessidade de investigar os conceitos advindos das experiências das pessoas a fim de elaborar estratégias de trabalho adequadas à real condição delas, estimulando o desenvolvimento pessoal, capaz de viabilizar ações em saúde significativas com base no êxito pessoal-coletivo ou coletivo-pessoal.

\section{Concepções sobre bem-estar e qualidade de vida}

Nesta análise, salienta-se a relação existente entre bem-estar e qualidade de vida e a sua vinculação direta com o que se concebe como saúde ou como doença, segundo as falas individuais e do grupo, revelando que todos os conceitos são emitidos considerando as perspectivas social, econômica, cultural e espiritual, e demonstrando que o modo de organização da sociedade 
influencia os valores das pessoas, direciona suas buscas e oportuniza doenças (Helman, 2009), como vemos na Figura 3.

Figura 3

Dinâmica das relações sociais e influências

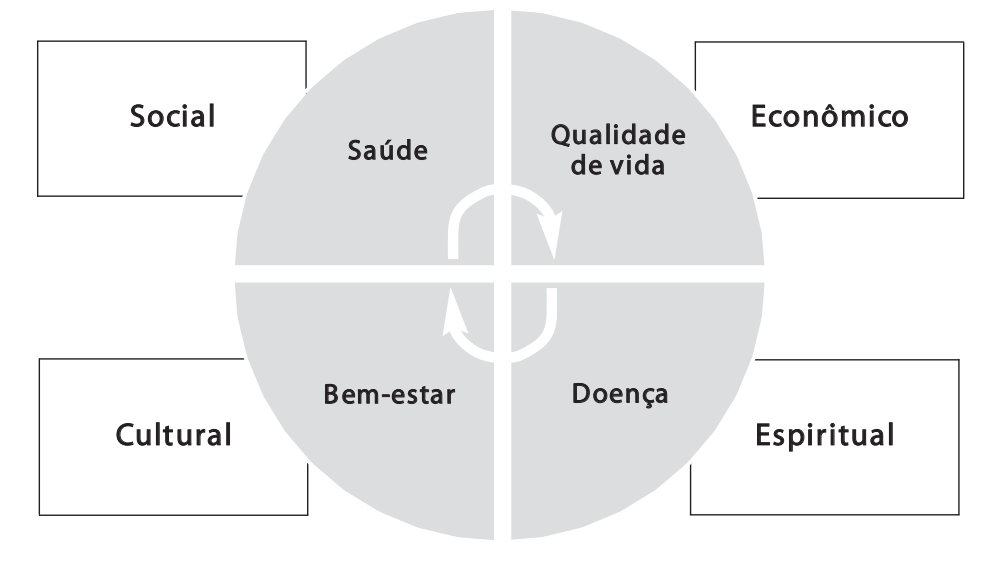

Fonte: Os autores.

As condições socioeconômicas das pessoas têm sido tema de muitos estudos quantitativos na saúde e foco de interesse de inúmeras políticas sociais. Porém, os resultados destes estudos não exprimem o contexto histórico-social das interferências e transformações na vida das pessoas provenientes de suas condições de vida e inter-relações com o contexto mais amplo relacionado ao território em que vivem, a situação político social, ambiental e educacional coletiva, algo que não se resume a uma avaliação associada às condições e aquisições individuais (Antunes, 2008).

A respeito desse assunto, Antunes (2008) cita dois paradigmas utilizados em estudos epidemiológicos para mensurar as condições socioeconômicas: 'liberdade e oportunidade' e 'igualdade e equidade'. O primeiro paradigma mostra que o conceito de liberdade se restringe à realização das potencialidades individuais e o de oportunidade trata do acesso a melhores condições de saúde. Já igualdade e equidade estão relacionadas a exploração e injustiça social. Aqueles que são privados materialmente têm dificuldades para ter acesso às condições de melhorias da saúde e, consequentemente, não podem gozar de boa saúde. Para o autor, é preciso refletir sobre essa forma de 'justiça social' que está posta em um contexto neoliberal, na qual os instrumentos podem dificultar nossa compreensão quanto às condições socioeconômicas e seu impacto sobre a saúde. 
Devemos levar em consideração que os parâmetros de onde emergem os conceitos dos docentes e da maioria dos autores citados neste artigo são resultado do pensamento neoliberal que influencia as pessoas de todas as classes sociais. Esses parâmetros estão presentes até mesmo em programas de entretenimento veiculados na mídia que mostram qualidade de vida e bem-estar atrelados a compras de bens, a um bom plano de saúde, a uma carreira de sucesso, fama e status social (Vasconcellos-Silva et al., 2010). Entre os docentes ficou clara a associação de que, para resolver alguns problemas sociais, você 'tem que ter'. Você deve buscar morar em lugares seguros, deve ter mais tempo para si mesmo, comer bem, pensar em coisas boas, investir em lazer, em educação etc.

Não atender ao que se preconiza como importante para o bem-estar e a qualidade de vida para os docentes significa não cuidar de si mesmo: passam então a se sentir culpados por não dedicar mais tempo a si mesmos e por não ter condições de investir em saúde. Com isso, começam a se preocupar excessivamente e a se cobrar além do que é realmente necessário, deixando de questionar o modo pelo qual as coisas são impostas. Apresentam temores quanto ao estado de saúde, não suportam uma condição física de enfermidade e na maioria das vezes buscam soluções e tratamento paliativos que apontam somente para o biológico como fonte única e eficaz de se alcançar saúde.

A saúde deve estar vinculada a distintas dimensões do viver humano (dimensão espiritual, dimensão cultural, dimensão educacional, dimensão ambiental, entre outras) e não apenas à dimensão biológica; não podemos excluir nenhuma das dimensões citadas, todas fazem parte dos seres humanos. Todavia, a dimensão biológica nos dias atuais tem sido o foco das atividades escolares, sobrepondo-se a outras dimensões maiores que a biológica, como a determinação social. Não somos um aglomerado de seres biológicos ou um conjunto de indivíduos. Pertencemos a uma dimensão social dinâmica que se articula com outras dimensões. Por isso mesmo, é importante que se reconheça o caráter social do processo saúde e doença no cotidiano humano (Bub, 2001).

Segundo Kluthcovsky e Takayanagui (2007), os aspectos conceituais sobre qualidade de vida vêm sofrendo mudanças, adquirindo mais sentido com o passar dos anos, considerando, além dos aspectos objetivos, os subjetivos - só que essa subjetividade também não é pura e, sim, influenciada por várias percepções. Porém, a relatividade dos conceitos é afetada pelos aspectos históricos, culturais e pelos padrões de bem-estar relacionados às camadas superiores. Além dessa subjetividade, também são consideradas a multidimensionalidade (física, psicológica e social), a bipolaridade (dimensões positivas e negativas) e a mutualidade (mudança em função do tempo, local, contexto cultural e pessoa). O melhor entendimento sobre o tema advém de uma busca intermitente pelas diversas áreas do conhecimento, 
avaliando pessoas em seus mais variados contextos de vida, contemplando os aspectos da vida numa dimensão socio-histórica e cultural, integrando conhecimentos ampliados que possam traduzir o viver.

Dentre outras falas, destacam-se, ainda, aspectos da relação entre alimentação e atividade física, bem como a superação de problemas na concepção de saúde e qualidade de vida. O cuidado com o corpo externa e internamente surge como uma forma de obtenção da saúde e de manutenção dela. O esforço individual e a disciplina são apontados como o meio para alcançá-la.

Nas falas, percebe-se que qualidade de vida está totalmente associada às condições de saúde, alimentação, mobilidade corporal e bem-estar, ao mesmo tempo em que a falta de integração desses aspectos pode levar ao adoecimento. O esforço individual para obtenção desse tipo de qualidade de vida também se torna notório, reforçando a teoria de responsabilização individual para se alcançar qualidade de vida e saúde.

Figura 4

Categorias relacionadas à qualidade de vida

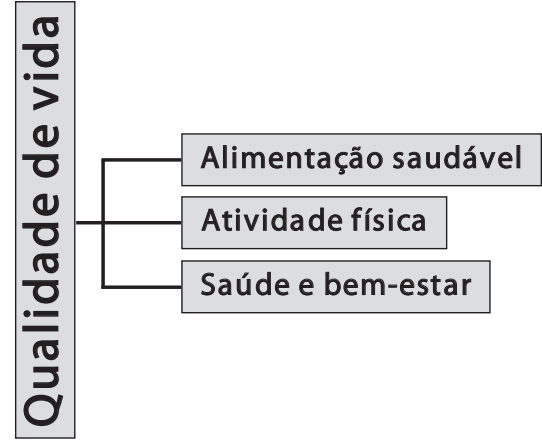

Fonte: Os autores.

Por outra parte, quando as pessoas estão inseridas em equipes de trabalho mais saudáveis, elas passam a desenvolver funções de forma mais competente e com maior comprometimento, usufruindo, assim, de melhor qualidade de vida. Contudo, alcançar esse nível de desempenho, tido como ideal, requer dedicação das duas partes: das organizações e da equipe de trabalho (Moscovici, 2005).

O trabalho relacionado com a educação em saúde sofre interferências diárias de ações da vida humana e tem relação direta com a qualidade de vida. Quando as pessoas se sentem desmotivadas com seu nível de bem-estar e 
qualidade de vida, ficam fragilizadas em sua saúde, comprometendo, assim, o desenvolvimento de ações em saúde no contexto escolar. O trabalhador realiza as práticas, mas não compreende significativamente as ações, considerando muitas dessas ações como uma obrigação, algo a ser cumprido em decorrência do currículo escolar, sem grandes motivações pessoais capazes de gerar mudanças. A maior motivação para o trabalho em saúde deve ser uma atividade prática sustentada na reflexão e na teoria. A atividade prática deve se conformar à teoria e essa, à prática. Uma questão de práxis individual em que a atividade prática é inseparável dos fins que a consciência traça, num processo de construção que sofre mudanças pelo próprio processo prático, que só termina quando o resultado ideal já é um produto real (Sánchez Vázquez, 1977).

Nessa concepção, teoria e prática são complementares e indissociáveis. Deve-se compreender a realidade, sobretudo, por meio de uma reflexão teórica para uma prática social transformadora que leve em consideração os aspectos objetivos e subjetivos. Falar de saúde, qualidade de vida, bem-estar e outros fenômenos do viver sem uma concepção prévia, elaborada a partir de uma reflexão crítica, baseada numa teoria que fundamente a ação, apenas contribuirá para a realização de atividades pedagógicas desarticuladas da realidade social, algo para o que Freire (2011) alertava quando falava sobre os saberes necessários à prática educativa.

\section{Condições para o desenvolvimento de ações em saúde na escola}

A participação dos pais na escola teve um importante destaque nas falas dos docentes, os quais ainda relatam que o desenvolvimento de qualquer ação em saúde somente terá efetividade se os pais se envolverem no processo. Para eles, a qualidade das ações depende diretamente da forma como as famílias compreendem saúde, qualidade de vida e bem-estar. Segundo os docentes, a partir do momento em que são trabalhadas atitudes favoráveis ao desenvolvimento da saúde, a família deve incentivar as ações de forma direta ou indireta, cooperando na elaboração e efetivação das práticas. Os conceitos modernos de educação e de promoção da saúde adotam uma abordagem participativa na comunidade escolar. Assim, entre os seis elementos apresentados por St Leger et al. (2007) destacamos três:

a) O ambiente social da escola, que é a qualidade das relações dos docentes e funcionários com alunos e desses entre si, influenciada pelas relações de qualidade com os pais e com a comunidade;

b) A ligação à comunidade, que consiste em conexões entre a escola e as famílias e com grupos ou pessoas-chave da comunidade que possam auxiliar a escola como promotora de saúde e oferecer aos alunos, docentes e funcionários o contexto e o apoio necessários para as suas ações; 
c) Os serviços de saúde, que são os serviços de saúde locais e regionais, próximos à escola ou dentro dela, com a responsabilidade dos cuidados de saúde e da promoção da saúde.

Entre os docentes, da mesma forma que os pais são responsabilizados, a área da saúde surge como coadjuvante no processo de saúde na escola. Eles precisam da presença dos profissionais na escola para dar suporte teórico e prático na rotina diária. Os docentes alegam falta de conhecimento para uma abordagem adequada e a inexistência de suporte pedagógico como material audiovisual, próteses, brinquedos pedagógicos e espaço físico adequado para atividades físicas e laborais.

Ainda de acordo com os docentes, os resultados das ações em saúde na escola são apenas temporários, sem muita abrangência, pois os alunos apresentam dificuldades maiores: nível socioeconômico baixo, ausência dos pais em casa, alimentação inadequada e alta rotatividade de professores durante os anos letivos. Isso dificulta a interação dos docentes e desestimula a elaboração de projetos de longo prazo como os que envolvem a saúde, pois abrangem questões complexas de ordem social.

Sobretudo, o fato é que ainda persiste uma escola fragmentada, compartimentada, que trabalha de forma mecanicista. Uma escola que resiste a mudanças, carregando o fardo do conservadorismo, que, por não conseguir dar respostas aos problemas, acaba sendo conflituosa (Moura et al., 2007).

\section{Considerações finais}

A implantação das ações em saúde é pouco satisfatória no contexto escolar e é até mesmo vista como sobrecarga de trabalho por parte de alguns docentes pela própria disparidade de conceitos sobre o que seja a responsabilidade da escola, a responsabilidade da área da saúde, a responsabilidade das famílias ou de outros órgãos. A falta de preparo da comunidade acadêmica expõe seus integrantes ao risco e impossibilita o desenvolvimento de ações concretas que auxiliem na qualidade de vida e bem-estar.

Percebemos nas falas dos docentes que a falta de educação permanente em saúde fragiliza e desfavorece a integração do ensino e da prática nesse contexto de promoção da saúde. A busca pela transformação da prática somente será possível se houver educação permanente em saúde com reflexão crítica sobre o modo de viver e as condições de trabalho. Isso contribuirá para a qualidade dos serviços, corroborando práticas autênticas.

Pelos discursos coletados, a visão do conceito de saúde por parte dos docentes já está sendo aprimorada para uma compreensão mais ampliada dos aspectos do viver, de modo a contribuir para uma vida mais significativa e capaz de considerar sua importância para si e para o outro (funcionários, 
colegas, alunos, famílias), produzindo ações que concorram para o desenvolvimento da escola de conformidade com a realidade local.

De acordo com a concepção de saúde, bem-estar, qualidade de vida e doença dos docentes a escola caminha para um pensamento reflexivo sobre suas práticas, voltado para a qualidade de vida de toda a comunidade acadêmica, a fim de produzir mudanças reais no estilo de vida, práticas de ensino e políticas sociais. Cônscios de sua fragilidade pessoal e profissional, mas receptivos a mudanças, eles consideram sua importância no processo de saúde e demonstram total interesse em desenvolver ações que estimulem aspectos da saúde individual e coletiva.

Um dos dados mais significativos do trabalho foi o de constatar que, apesar dos obstáculos referidos e dificuldades pessoais, o grupo sente-se muito confortável quanto ao trabalho coletivo, e suas opiniões não são conflitantes, mas harmoniosas até mesmo na heterogeneidade de saberes. A corresponsabilização com a sociedade para alcançar saúde, bem-estar e qualidade de vida foi muito evidente e não descaracteriza o trabalho docente, apenas amplia a maneira de ver e viver saúde.

Pelo modo como foram qualificados os quatro fenômenos do viver citados, entendemos que a saúde é um processo modelado pelas condições físicas, emocionais e socioeconômicas, e que a doença é uma limitação física ou psicológica que pode ser superada pelo psicossocial aliado ao espiritual. No que se refere à qualidade de vida, o que mais importa é a expectativa de saúde alcançada, juntamente com o êxito nas metas individuais e profissionais.

\section{Colaboradores}

Ioná Outo de Souza Wilberstaedt, Marcia Gilmara Marian Vieira e Yolanda Flores e Silva trabalharam em conjunto na realização da pesquisa e da escrita do artigo. 
Resumen La investigación tuvo por objetivo conocer las concepciones sobre salud, enfermedad, calidad de vida y temas afines de docentes de una escuela pública de Florianópolis, Santa Catarina, Brasil, 2013. Estudio cualitativo, de naturaleza descriptiva, con datos colectados por medio de grupo focal y entrevistas semiestructuradas. La estrategia de grupo focal adoptada fue orientada según el abordaje del 'círculo de cultura', en el cual los participantes expresaron sus concepciones sobre los temas estudiados y reflejan sobre como contribuir con estrategias de promoción de la salud en el contexto escolar por medio de educación en salud. El universo de la investigación fue formado por 16 docentes de la red estadual de enseño; ocho docentes confirmaron la participación en el grupo focal y, de esos, apenas seis comparecieron del primero al último encuentro. Al final los datos revelaron que los docentes perciben una estrecha relación entre salud y calidad de vida y que una vida saludable es posible en la presencia de enfermedad. Enfatizaron la necesidad de mayor participación de los padres y profesionales de la salud en el proceso de educación en salud $\mathrm{y}$, también, de un preparo sistemático y permanente sobre las cuestiones que envuelven salud en el contexto escolar. Las concepciones de los docentes reafirman que la dimensión social sobresale a la biológica y que el conocimiento y la valorización de esos aspectos, en la práctica docente, pueden ampliar las acciones en salud.

Palabras clave salud; calidad de vida; docentes.

\section{Notas}

1 Secretaria do Estado de Educação, Escola Estadual de Educação Básica Joaquim Santiago, São José, Santa Catarina, Brasil.

<iona.outo@yahoo.com.br>

Correspondência: Escola Estadual de Educação Básica Joaquim Santiago, Rua Zita Althoff Koerich, 1.744, Colônia Santana, CEP 88123-100, São José, Santa Catarina, Brasil.

2 Universidade do Vale do Itajaí, Programa de Mestrado em Saúde e Gestão do Trabalho, Itajaí, Santa Catarina, Brasil.

$<$ mmarian@univali.br>

3 Universidade do Vale do Itajaí, Programa de Mestrado em Saúde e Gestão do Trabalho, Itajaí, Santa Catarina, Brasil.

<yolanda@univali.br>

4 Este artigo apresenta parte dos resultados da dissertação de Ioná Outo de Souza Wilberstaedt, apresentada no Mestrado Profissional em Saúde e Gestão do Trabalho, da Universidade do Vale do Itajaí, Santa Catarina, intitulada Saúde e qualidade de vida: discursos do corpo docente de uma escola pública estadual de ensino fundamental da capital catarinense. A dissertação foi orientada e coorientada pelas professoras Yolanda Flores e Silva e Márcia Gilmara Marian Vieira. 


\section{Referências}

AERTS, Denise et al. Promoção de saúde: a convergência entre as propostas da vigilância da saúde e da escola cidadã. Cadernos de Saúde Pública, Rio de Janeiro, v. 20, n. 4, p.1020-1028, ago. 2004. Disponível em: <www. scielo.br/scielo.php?script $=$ sci_arttext\&pid $=$ S0102-311X2004000400017\&lng=pt\&nrm=iso $>$. Acesso em: 8 jun. 2014.

ANTUNES, José L. F. Condições socioeconômicas em saúde: discussão de dois paradigmas. Revista de Saúde Pública, São Paulo, v. 42, n. 3, p. 562-567, jun. 2008. Disponível em: $<$ www.scielo.br/scielo.php?script $=$ sci_ arttext\&pid $=$ S0034-89102008000300025\& lng=pt\&nrm=iso >. Acesso em: 5 jun. 2014.

ARAUJO, Marize B. S.; ROCHA, Paulo M. Trabalho em equipe: um desafio para a consolidação da Estratégia de Saúde da Família. Ciência \& Saúde Coletiva, Rio de Janeiro, v. 12, n. 2, p. 455-464, abr. 2007. Disponível em: $<$ www.scielo.br/scielo.php?script $=$ sci_ arttext\&pid=S1413-81232007000200022\&lng= pt\&nrm=iso >. Acesso em: 9 jun. 2014.

ASCHIDAMINI, Ione M.; SAUPE, Rosita. Grupo focal: estratégia metodológica qualitativa: um ensaio teórico. Revista Cogitare Enfermagem, Curitiba, v. 9, n. 1, p. 9-14, 2004.

AYRES, José R. C. M. Uma concepção hermenêutica de saúde. Physis: Revista de Saúde Coletiva, Rio de Janeiro, v. 17, n. 1, p. 43-62, abr. 2007. Disponível em: <www.scielo.br/ scielo.php?script=sci_arttext $\&$ pid $=$ S0103$73312007000100004 \& \operatorname{lng}=\mathrm{pt} \& \mathrm{nrm}=$ iso $>$. Acesso em: 9 jun. 2014.

BUB, Maria B. C. Concepções de saúde, ética e prática de enfermagem. 2001. $126 \mathrm{fl}$. Tese (Doutorado em Enfermagem) - Universidade Federal de Santa Catarina, Florianópolis, 2001.

BUSS, Paulo M. Promoção da saúde e qualidade de vida. Ciência \& Saúde Coletiva, Rio de Janeiro, v. 5, n. 1, p. 163-177, 2000. Disponível em: $<$ www.scielo.br/scielo.php?script=
sci_arttext\&pid=S1413-81232000000100014\& lng $=$ pt\&nrm $=$ iso $>$. Acesso em: 5 jun. 2014.

CAMPOS, Maryane O.; RODRIGUES NETO, João F. Qualidade de vida: um instrumento para promoção de saúde. Revista Baiana de Saúde Pública, Salvador, v. 32, n. 2, p. 232-240, maio-ago. 2008.

CANGUILHEM, Georges. O normal e o patológico. 6. ed. Rio de Janeiro: Forense Universitária, 2009.

DALMOLIN, Bárbara B. et al. Significados do conceito de saúde na perspectiva de docentes da área da saúde. Escola Anna Nery, Rio de Janeiro, v. 15, n. 2, p. 389-394, abr.-jun. 2011.

FOUCAULT, Michel. O nascimento da clínica. 6 . ed. Rio de Janeiro: Forense Universitária, 2008.

FREIRE, Paulo. Pedagogia da autonomia: saberes necessários à prática educativa. São Paulo: Paz e Terra, 2011.

FREIRE, Paulo. Educação como prática da liberdade. 14. ed. Rio de Janeiro: Paz e Terra, 1983

FREIRE, Paulo. Conscientização: teoria e prática da libertação: uma introdução ao pensamento de Paulo Freire. 3. ed. 2. reimp. São Paulo: Centauro, 2008.

GEERTZ, Clifford. O saber local: novos ensaios em antropologia interpretativa. Petrópolis: Vozes, 1997.

GOMES, José P. As escolas promotoras de saúde: uma via para promover a saúde e a educação para a saúde da comunidade escolar. Educação, Porto Alegre, v. 32, n. 1, p. 84-91, jan.-abr. 2009.

HELMAN, Cecil. Culture, health and illness: an introduction for health professionals. London: John Wright \& And Sons Ltda., 2014.

HELMAN, Cecil. Cultura, saúde e doença. Porto Alegre: Artmed, 2009. 
KLUTHCOVSKY, Ana C. G. C.; TAKAYANAGUI, Angela M. M. Qualidade de vida: aspectos conceituais. Revista Salus, Paraná, v. 1, n. 1, p. 13-15, jan.-jun. 2007.

LANGDON, Esther J.; WIIK, Flávio B. Antropologia, saúde e doença: uma introdução ao conceito de cultura aplicado às ciências da saúde. Revista Latino-Americana de Enfermagem, Ribeirão Preto, v. 18, n. 3, p. 173-181, jun. 2010. Disponível em: <www.scielo.br/scielo. php? script $=$ sci_arttext \& pid $=$ S0 104 $11692010000300023 \& \operatorname{lng}=$ pt $\& \mathrm{nrm}=$ iso $>$. Acesso em: 7 jun. 2014.

LEFÈVRE, Fernando; LEFÈVRE, Ana M. C. Promoção de saúde: a negação da negação. Rio de Janeiro: Vieira e Lent, 2004.

MACHADO, Maria F. A. S. et al. Integralidade, formação de saúde, educação em saúde e as propostas do SUS: uma revisão conceitual. Ciência \& Saúde Coletiva, Rio de Janeiro, v. 12, n. 2, p. 335-342, abr. 2007. Disponível em: $<$ www.scielo.br/scielo.php?script $=$ sci_ arttext\&pid=S1413-81232007000200009\&lng= en\&nrm=iso >. Acesso em: 9 jul. 2014.

MARGIS, Regina et al. Relação entre estressores, estresse e ansiedade. Revista de Psiquiatria do Rio Grande do Sul, Porto Alegre, v. 25, supl. 1, p. 65-74, abr. 2003. Disponível em: $<$ www.scielo.br/scielo.php?script $=$ sci_ arttext\&pid=S0101-81082003000400008\&lng= pt\&nrm=iso $>$. Acesso em: 10 jul. 2014.

MINAYO, Maria C. S. (org.). Pesquisa social: teoria, método e criatividade. 28 ed. Petrópolis: Vozes, 2009.

MINAYO, Maria C. S. O desafio do conhecimento: pesquisa qualitativa em saúde. São Paulo: Hucitec, 2007.

MINAYO, Maria C. S.; SANCHES, Odécio. Quantitativo-Qualitativo: Oposição ou complementaridade? Cadernos de Saúde Pública, Rio de Janeiro, v. 9, n. 3, p. 239-262, jul.-set., 1993.

MOSCOVICI, Fela. Equipes dão certo: a multiplicação do talento humano. 10. ed. Rio de Janeiro: José Olympio, 2005.
MOURA, João B. V. S. et al. Perspectiva da epistemologia histórica e a escola promotora de saúde. História, Ciências, Saúde-Manguinhos, Rio de Janeiro, v. 14, n. 2, p. 489-501, jun. 2007. Disponível em <www.scielo.br/scielo. php?script $=$ sci_arttext \&pid $=$ S010459702007000200006\&lng =pt\&nrm $=$ iso $>$. Acesso em: 13 jul. 2014.

NAHAS, Markus V.; BARROS, Mauro V. G.; FANCALACCI, Vanessa. O pentáculo do bem estar: base conceitual para avaliação do estilo de vida de indivíduos ou grupos. Revista Brasileira de Atividade Física \& Saúde, Londrina, v. 5, n. 2, p. 48-59, 2000.

NOGUEIRA-MARTINS, Maria C. F.; BOGUS, Cláudia M. Considerações sobre a metodologia qualitativa como recurso para o estudo das ações de humanização em saúde. Saúde e Sociedade, São Paulo, v. 13, n. 3, p. 44-57, dez. 2004. Disponível em: <www.scielo.br/ scielo.php?script $=$ sci_arttext \&pid $=$ S0104$12902004000300006 \& \operatorname{lng}=p t \& n r m=i s o>$. Acesso em: 16 jun. 2014.

ORGANIZAÇÃO MUNDIAL DA SAÚDE. Carta da Organização Mundial da Saúde, 1946. Disponível em: <www.onuportugal. pt/oms.doc>. Acesso em: 12 abr. 2014.

PEROSA, Cleci T.; PEDRO, Eva N. R. Perspectivas de jovens universitários da região norte do Rio Grande do Sul em relação à paternidade. Revista Escola Enfermagem USP, São Paulo, v. 43, n. 2, p. 300-306, jun. 2009. Disponível em: <www.scielo.br/ scielo.php?script $=$ sci_arttext $\&$ pid $=$ S0080 $62342009000200007 \& \operatorname{lng}=$ pt $\& n r m=$ iso $>$. Acesso em: 12 jul. 2014.

ROCHA, Vera M.; FERNANDES, Marcos H. Qualidade de vida de professores do ensino fundamental: uma perspectiva para a promoção da saúde do trabalhador. Jornal Brasileiro de Psiquiatria, São Paulo, v. 57, n. 1, p. 23-27, 2008.

ST LEGER, Laurence; KOLBE, Lloyd; McCALL, Douglas; LEE, Albert; YOUNG, Ian. School health promotion global perspectives on health promotion effectiveness. New 
York: Springer Science and Business Media, 2007. p. 107-124 / doi: 10.1007/978-0-38770974-1_8.

TURATO, Eg berto R. Métodos qualitativos e quantitativos na área da saúde: definições, diferenças e seus objetos de pesquisa. Revista de Saúde Pública, São Paulo, v. 39, n. 3, p. 507-514, jun. 2005. Disponível em: $<$ www.scielo.br/scielo.php?script $=$ sci_ arttext\&pid=S0034-89102005000300025\&lng= pt\&nrm=iso >. Acesso em: 12 jul. 2014.
VASCONCELLOS-SILVA, Paulo R. et al. As novas tecnologias da informação e o consumismo em saúde. Cadernos de Saúde Pública, Rio de Janeiro, v. 26, n. 8, p. 1.473-1.482, ago, 2010 .

VAZQUEZ, Adolfo S. Filosofia da práxis. 2. ed. Rio de Janeiro: Paz e Terra, 1977.

Recebido em 07/07/2014

Aprovado em 06/04/2015 